\title{
Breeding Biology Research and Data Availability for New World Flycatchers
}

\author{
Neander M. Heming ${ }^{1 *}$, Harold F. Greeney ${ }^{2} \&$ Miguel Â. Marini ${ }^{3}$
}

${ }^{1}$ Programa de Pós-graduação em Ecologia, Instituto de Ciências Biológicas - IB, Universidade de Brasília - UnB, Brasília, DF, Brasil

2 Yanayacu Biological Station \& Center for Creative Studies, Napo Prov., Cosanga, Ecuador

${ }^{3}$ Departamento de Zoologia, Instituto de Ciências Biológicas - IB, Universidade de Brasília - UnB, Brasília, DF, Brasil

\begin{abstract}
Life-history strategies of Neotropical birds differ markedly from their Nearctic counterparts, yet the lack of detailed information on most Neotropical species hinders meaningful comparisons. We performed a gap analysis with several basic life-history traits of New World flycatchers of the subfamily Fluvicolinae. We found breeding data - mostly on clutch sizes and linear egg measurements - in 303 publications spanning the years 1838 to 2012. Data from the USA and Argentina were more abundant, with the number of publications per country being significantly and positively related to human development index (HDI) and Fluvicolinae breeding species richness. The amount of available clutch size information for each species was positively related to species' range size and relative abundance. More research is needed concerning narrowly distributed and uncommon species. Additional efforts to gather data on all Neotropical species are, however, crucial for future advancements.
\end{abstract}

Key words: Life-History, Reproduction, Neotropical Ornithology, Scientific Development, Avian Research.

\section{Introduction}

Life-history theory has matured considerably since the publications of Lack (1947), Skutch (1949), and Moreau (1944) (details in Ricklefs 2000). These pioneering works gave avian breeding biology a fundamental role in the development of life-history evolution theory (Partridge \& Harvey 1988) - in particular the examination of geographic variation in clutch size (Martin 2004) - and sparked a rich literature formulating and refining hypotheses to explain observed patterns (Ricklefs 2000).

Life-history strategies of Southern Hemisphere birds differ markedly from their northern counterparts, with southern species having smaller clutch sizes, larger eggs, longer development periods, higher adult survival and slower metabolism (e.g., Moreau 1944; Skutch 1949; Ricklefs \& Brawn 2013). In addition, species throughout the South temperate New World exhibit life-history traits more similar to tropical species than from those of Nearctic species (Martin 1996, 2004). However, there is no consensus about the processes that generate these patterns (Martin 2004), in part because available data have not been satisfactorily

*Send correspondence to: Neander Marcel Heming Programa de Pós-graduação em Ecologia, Instituto de Ciências Biológicas - IB, Universidade de Brasília - UnB, CEP 70910-900, Brasília, DF, Brasil

E-mail: neanderh@yahoo.com.br linked to theory (Vuilleumier 2004). In addition, the relative lack of basic information for most Southern Hemisphere species (Martin 1996; Alves et al. 2008) continues to hinder our ability to understand possible explanations for observed latitudinal variations (Martin 1996).

Information gap analyses are valuable tools for guiding future research, helping to identify what has been done in a specific scientific area, and suggesting ways to improve upon existing work (e.g., Azevedo et al. 2010; Nabout et al. 2010). With a review of published literature, we quantify the state of knowledge on several basic life-history traits of the Fluvicolinae (e.g., clutch size, egg measurements, egg weight, and incubation and nestling periods), and describe the distribution of information with respect to publication language, country where the data was gathered, specific life-history traits, and species studied. We also ask if the distribution of information is related to several additional variables (e.g., human development index, species relative abundance, and breeding range size). In light of our findings we make suggestions for filling regional and taxonomic gaps.

\section{Material and Methods}

We reviewed the literature for data on Fluvicolinae breeding biology (details in Additional Supporting Information available at www.abeco.org.br - SI hereafter), and obtained 
breeding data and location (latitude and longitude) from literature records (details in SI).

\section{Life-history traits}

We surveyed five breeding traits (clutch size, linear egg measurements, egg weight, and incubation and nestling periods) because they have been more often described for New World birds (see SI).

\section{Comparisons and statistical analyses}

We summed all records reported in the literature (details in SI). We examined the distribution of publications by language and by country, describe the availability of data for each of five breeding traits (clutch sizes, egg size, egg weights, and incubation and nestling periods).

We also tested the explanatory power of several variables on the distribution of clutch records (for details on data sources, why the variables were used, and residual autocorrelation tests see SI). For countries, we used as predictors the Human Development Index (HDI), breeding Fluvicolinae species richness, and country-level bird richness (Table S3 in Additional Supporting Information available at www.abeco. org.br). We tested which species' characteristics - range size, relative abundance, and of the species' sampling potential index (SSPI) - were the best predictors of sampling completeness (Table S4).

\section{Results}

We found relevant breeding information for fluvicolines in 300 publications (see SI) spanning the years 1838 to 2012. The annual number of publications increased through time (Figure S1). Most publications were written in English $(\mathrm{N}=210)$. We found publications from 26 countries, with the majority from Argentina $(\mathrm{N}=75)$, United States of America (USA) $(\mathrm{N}=64)$, and Brazil $(\mathrm{N}=42$, Figure 1, Table S3). Studies conducted in the USA accounted for the greatest number of clutches $(\mathrm{N}=2,086)$ and eggs measured $(\mathrm{N}=1,402)$, followed by Argentina (1,275 and 1,087, respectively). All other countries had less than 310 records each, of all traits (Figure 1, Table S3). The number of publications per country was significantly and positively related to HDI and fluvicoline species richness (Table 1).

In total, we found 4,751 clutch sizes, 3,952 linear egg measurements, 1,152 egg weights, 349 incubation periods, and 285 nestling periods. Data were not evenly distributed taxonomically, with most records pertaining to only a few species (Figure 2, Table S4). Data on clutch size were completely lacking for 43 species, linear egg measurements

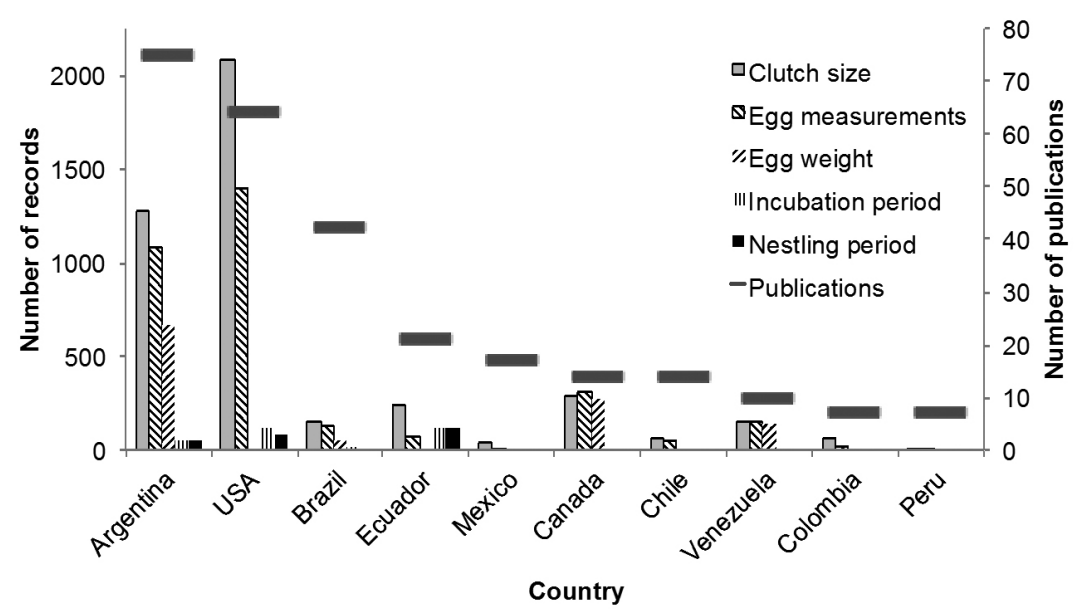

Figure 1. Number of publications and clutch size, linear egg measurements, egg weight, incubation period, and nestling period records of Fluvicolinae found in the literature review for each of the 10 best-sampled countries.

Table 1. GLM results of human development index (HDI), Fluvicolinae species richness, and bird richness as predictors of variation in the number of publications found for Fluvicolinae in the New World countries analyzed $(\mathrm{N}=29)$. Significant values in bold.

\begin{tabular}{lcccccc}
\hline \multicolumn{1}{c}{ Term } & Estimate & SE & P value & Resid. df & $\begin{array}{c}\text { Deviance } \\
\text { explained (\%) }\end{array}$ & $\begin{array}{c}\text { Residual } \\
\text { deviance }\end{array}$ \\
\hline (Intercept) & $\mathbf{- 8 . 4 5}$ & 1.85 & $<0.001$ & 28 & & 584 \\
HDI & $\mathbf{1 2 . 1 8}$ & 2.03 & $<0.001$ & 27 & 38.0 & 362 \\
Fluvicolinae spp. richness & $\mathbf{0 . 0 4}$ & 0.012 & 0.002 & 26 & 36.1 & 151 \\
Total Bird Richness & 0.0004 & 0.0005 & 0.373 & 25 & 0.7 & 147 \\
\hline
\end{tabular}


for 47 species, egg weights for 100 species, incubation periods for 100 species, and nestling periods for 105 species. Also, 38 out of the 131 species and three (Aphanotriccus, Cnemarchus, and Tumbezia) out of 38 genera had no pertinent breeding data whatsoever (Table S4).

The number of clutch size records available for each species was positively related to species breeding area and SSPI (Table 2). Uncommon species had fewer records than common species (Table 2). Breeding area, relative abundance, and SSPI explained $31.7 \%, 17.5 \%$, and 5.7\%, respectively, of variation in the amount of information available (Table 2).

\section{Discussion}

Recently, the number of avian breeding papers published annually has increased, as is the case in other research areas (see examples in Nabout et al. 2010). The increase in publications containing fluvicoline breeding data mirrors the general expansion of Neotropical ornithology (James 1987; Vuilleumier 2003; Freile 2005) and increasing investments in natural history museums, universities, and human resources in countries such as Brazil (Alves et al. 2008; Borges 2008) and Colombia (Naranjo 2008). Indeed, Neotropical ornithology has blossomed even in countries (e.g., Ecuador) where the local economic and political situations have not been favourable (Freile 2005).

HDI was positively related to, and explained most of the variation in, the number of publications. The number of published articles is usually closely tied to a country's per capita income (e.g., Nabout et al. 2010), and a country's research development is closely linked to its investment in infrastructure and education. Such resource allocation leads to the formation and expansion of universities and natural history museums (Freile 2005; Alves et al. 2008; Nabout et al. 2010).

The richness of the fluvicoline breeding fauna in a given country explained $36.1 \%$ of the variation in that country's number of publications. That more species generate more papers is unsurprising, and this correlation varies geographically, as it is also influenced by other variables. Argentina, for example, has produced a large number of publications and is also among the most fluvicoline-rich countries (54 species), but this country also has the longest tradition of ornithological research in Latin America (Asociación Ornitológica del Plata was founded in 1916, www.avesargentinas.org.ar). On the other hand, some fluvicoline-rich countries are relatively publication-poor, in part due to their relatively late emphasis on breeding biology

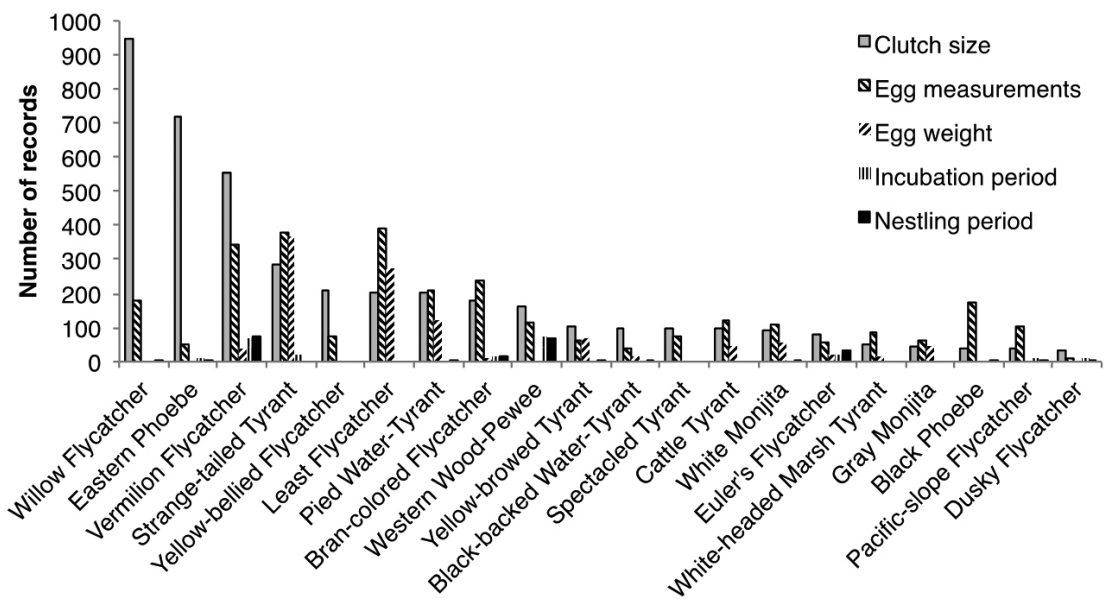

Figure 2. Number of records of clutch size, linear egg measurements, egg weight, incubation period, and nestling period records for each Fluvicolinae species in the literature review in the New World.

Table 2. Results of a GLM testing species breeding range size, relative abundance (RA), and species sampling potential index (SSPI) as predictors of variation in the number clutch size records found for each species of Fluvicolinae $(\mathrm{N}=131)$ in the New World. Significant values in bold.

\begin{tabular}{|c|c|c|c|c|c|c|}
\hline Term & Estimate & SE & $P$ value & Resid. df & $\begin{array}{c}\text { Deviance } \\
\text { explained (\%) }\end{array}$ & $\begin{array}{l}\text { Residual } \\
\text { deviance }\end{array}$ \\
\hline (Intercept) & -1.07 & 2.04 & $<0.001$ & 130 & & 17862 \\
\hline Breeding area & $2.90 \mathrm{E}-07$ & $6.12 \mathrm{E}-08$ & $<0.001$ & 129 & 31.7 & 12193 \\
\hline RA (Fairly common) & -0.89 & 0.52 & 0.089 & 126 & 17.5 & 9065 \\
\hline RA (Uncommon) & -1.37 & 0.65 & 0.037 & & & \\
\hline RA (Rare) & -1.80 & 3.22 & 0.578 & & & \\
\hline SSPI & 0.06 & 0.025 & 0.017 & 125 & 5.7 & 8051 \\
\hline
\end{tabular}


studies (e.g., Brazil, 38 species, Alves et al. 2008; Borges 2008; Bolivia, 53; Colombia, 43, Naranjo 2008; Ecuador, 43, Freile 2005; Peru, 61; see Table S1). Biodiversity and distribution data often show geographic biases (i.e., uneven sampling across sites), the known species richness usually increases with research effort, and thus the knowledge of both species' distributions and country richness are not necessarily accurate (Sastre \& Lobo 2009). Here we assume that fluvicoline country richness is at least moderately accurate and the richness reflects the probability of the breeding biology of any species being studied, however the richness-publication relationship should be interpreted with caution.

Data collection is usually biased towards a few species or sites, due to restricted access, species abundance, and available human resources (e.g., Borges 1995; Peterson et al. 1998). Such sampling biases create the observed pattern of unequal country-level publication production (Table S1), a scenario that limits our ability to understand the spatial variation in life-history traits. In order to increase scientific knowledge of the biology of the Fluvicolinae and other avian groups, we must facilitate research by increasing the number of high-quality academic institutions in the Neotropics (Rodríguez et al. 2005). Furthermore, we must establish or improve international networks such as Aves Internacionales (biology.ufl.edu/centers/migration/aves), and eBird.

There are also biases in the type of life-history trait collected in the field. Data are relatively abundant for clutch sizes and linear egg measurements, whereas egg weights, and incubation and nestling periods are poorly sampled for most species. These traits were insufficiently sampled even for abundant species, with broad geographic ranges, and whose nests are found with regularity. Not surprisingly, both of these (relatively) better-sampled traits are easier data to gather in the field when faced with time or logistical constraints. Clutch size and linear egg measurements only require finding the nest, not monitoring it (Marini et al. 2010). This reinforces the conclusion that studies rarely last long enough to provide data on traits that may be important for theoretical advances (Russell 2000). Data on developmental periods require, in addition to time for nest searching, continuous monitoring of nests for at least a few weeks (Marini et al. 2010). If we also take into account the number of nests depredated before completion (e.g., Skutch 1985), dozens of nests must be found in order to collect this information for even a few. Egg weights were probably not taken in the past because portable, cheap, and precise scales have only recently become widely available. Clearly, researchers have to increase the amount of data for Neotropical species if we wish to more rigorously test hypotheses, compare geographic regions, and facilitate theoretical progress towards the proposal of next-generation hypotheses.

Moreover, very few species have been thoroughly sampled, even in countries with relatively well-studied fauna such as the USA and Argentina. Common and broadly distributed species are usually better known, with a few notable exceptions where a species has been targeted by particular research teams (e.g., Alectrurus risora, di Giacomo et al. 2011). Our results are consistent with earlier findings, in which geographic ranges and abundance explain over $60 \%$ and $30 \%$, respectively, of the variance of discovery dates of oscine passerine birds (Blackburn \& Gaston 1995). This and our results suggest that species with narrow distributions are usually discovered later and, after that, their biology remains unsatisfactorily known or unknown, especially in countries without much research support.

Our examination of breeding data for fluvicoline flycatchers confirms and reinforces the general lack of avian life-history data (Martin 1996; Russell 2000), species-specific deficiencies (Martin 1996; Russell 2000; Alves et al. 2008), and uneven geographic distribution of information (Borges 1995; Peterson et al. 1998). To fill these gaps, more research is needed concerning narrowly distributed and uncommon species. Short-term studies (e.g., single breeding season) are enough to describe clutch sizes, linear egg measurements, weights, incubation and nestling periods, but data on other traits such as post-fledging parental care, and juvenile and adult survival are almost non-existent for most species. In fact, even for the better-studied Northern Hemisphere fauna, studies of breeding biology do not collect data beyond fledging, and largely ignore what may be a crucial life-history phase effecting the evolution of breeding strategies (Martin 1996; Russell 2000; Ricklefs \& Brawn 2013). We suggest that these data are more likely to be gathered in the future if medium- and long-term studies are given preferential support.

Our need for an increased focus on the gathering of basic life-history data is emphasized by the fact that, though for more than a century ornithologists have discussed geographic variation in avian life-history traits (Moreau 1944; Lack 1947; Skutch 1949, 1985), we are still far from explaining it (e.g., Ricklefs 2000; Martin 2004). Modern ornithologists have a plethora of new research tools available to them, such as internet access to data and publications, increasingly affordable and sophisticated molecular techniques, data loggers, GIS mapping, etc.; even so, it is clear that we must continue to gather and publish descriptive natural history data, which requires little more than paper, pen, and persistence. Sadly, the collection and dissemination of this type of data is something that has been devalued in modern academia, even though it was historically prized by biologists and despite the fact that the lack of such data may be hindering theoretical advancement (Futuyma 1998). Modern ornithologists now have many unique advantages over their predecessors, yet we strongly suggest that a return to the "boots on the ground" approach of generations past will not only be richly rewarding to the student of biology, but will provide an opportunity to contribute directly to advances in life-history theory. 


\section{Acknowledgments}

We thank to Serviço de Biblioteca e Documentação MZUSP for helping with the literature, and R.H. Macedo, R.J. Young, R.B. Machado, J.S. Marinho-Filho, A.C. Guaraldo, D.T. Gressler, L.M. Bini, and anonymous reviewers for suggestions and comments. We were supported by Conselho Nacional de Desenvolvimento Científico e Tecnológico (CNPq), Coordenação de Aperfeiçoamento de Pessoal de Nível Superior (CAPES), and Fundação de Apoio a Pesquisa do Distrito Federal (FAP-DF).

\section{References}

Alves MAS, Silva JMC \& Costa ES, 2008. Brazilian ornithology: History and current trends. Ornitología Neotropical, 19:391-399.

Azevedo PG, Mesquita FO \& Young RJ, 2010. Fishing for gaps in science: a bibliographic analysis of Brazilian freshwater ichthyology from 1986 to 2005. Journal of Fish Biology, 76:2177-2193. http://dx.doi. org/10.1111/j.1095-8649.2010.02668.x

Blackburn TM \& Gaston KJ, 1995. Special Paper: What Determines the Probability of Discovering a Species?: A Study of South American Oscine Passerine Birds. Journal of Biogeography, 22:7-14. http://dx.doi.org/10.2307/2846069

Borges SH, 1995. As teses de pós-graduação produzidas no Brasil na área de ornitologia entre 1970 e 1991. Revista Brasileira de Ornitologia, 3:33-36.

Borges SH, 2008. The relevance of graduate teachings in the formation of human resources for biodiversity studies in Brazil: a case study in ornithology. Biota Neotropica, 8:21-27.

di Giacomo AG, di Giacomo AS \& Reboreda JC, 2011. Effects of grassland burning on reproductive success of globally threatened Strange-tailed Tyrants Alectrurus risora. Bird Conservation International, 21:411-422. http://dx.doi. org/10.1017/S0959270910000584

Freile JF, 2005. Gustavo Orcés, Fernando Ortiz y el desarrollo de la ornitología hecha en Ecuador. Ornitología Neotropical, 16:321-336.

Futuyma DJ, 1998. Wherefore and Whither the Naturalist? The American Naturalist, 151:1-6. http://dx.doi. org/10.1086/286097

James PC, 1987. Ornithology in Central and South America. The Auk, 104:348-349.

Lack D, 1947. The significance of clutch size. The Ibis, 89:302352. http://dx.doi.org/10.1111/j.1474-919X.1947.tb04155.x

Marini MÂ, Duca C \& Manica LT, 2010. Técnicas de pesquisa em biologia reprodutiva de aves. In: Matter SV, Piacentini VQ, Straube FC, Cândido JF Jr \& Accordi IA (eds.). Ornitologia e Conservação: Ciência Aplicada, Técnicas de Pesquisa e Levantamento. Rio de Janeiro: Technical Books. p. 295-312.

Martin TE, 1996. Life history evolution in tropical and south temperate birds: what do we really know? Journal of Avian Biology, 27:263-272. http://dx.doi.org/10.2307/3677257
Martin TE, 2004. Avian life-history evolution has an eminent past: does it have a bright future? The Auk, 121:289-301. http://dx.doi.org/10.1642/0004-8038(2004)121[0289:ALEH $\mathrm{AE}] 2.0 . \mathrm{CO} ; 2$

Moreau RE, 1944. Clutch-size: a comparative study, with special reference to African birds. Ibis, 86:286-347. http://dx.doi. org/10.1111/j.1474-919X.1944.tb04093.x

Nabout JC, Bini LM \& Diniz-Filho JAF, 2010. Global literature of fiddler crabs, genus Uca (Decapoda, Ocypodidae): trends and future directions. Iheringia. Série Zoologia, 100:463-468. http://dx.doi.org/10.1590/S0073-47212010000400019

Naranjo LG, 2008. El arcano de la ornitología Colombiana. Ornitología Colombiana, 7:5-16.

Partridge L \& Harvey PH, 1988. The ecological context of life history evolution. Science, 241:1449-1455. http://dx.doi. org/10.1126/science.241.4872.1449

Peterson AT, Navarro-Sigüenza AG \& Benítez-Díaz H, 1998. The need for continued scientific collecting; a geographic analysis of Mexican bird specimens. Ibis, 140:288-294. http://dx.doi.org/10.1111/j.1474-919X.1998.tb04391.x

Ricklefs RE, 2000. Lack, Skutch, and Moreau: the early development of life-history thinking. The Condor, 102:3-8. http://dx.doi.org/10.1650/0010-5422(2000)102[0003:LSAM TE]2.0.CO;2

Ricklefs RE \& Brawn J, 2013. Nest attentiveness in several Neotropical suboscine passerine birds with long incubation periods. Journal of Ornithology, 154:145-154. http://dx.doi. org/10.1007/s10336-012-0880-9

Rodríguez JP et al., 2005. Conservation in Austral and Neotropical America: building scientific capacity equal to the challenges. Conservation Biology, 19:969-972. http:// dx.doi.org/10.1111/j.1523-1739.2005.00555.x

Russell EM, 2000. Avian life histories: is extended parental care the southern secret? Emu, 100:377-399. http://dx.doi. org/10.1071/MU0005S

Sastre P \& Lobo JM, 2009. Taxonomist survey biases and the unveiling of biodiversity patterns. Biological Conservation, 142:462-467.

Skutch AF, 1949. Do tropical birds rear as many young as they can nourish? The Ibis, 91:430-455. http://dx.doi. org/10.1111/j.1474-919X.1949.tb02293.x

Skutch AF, 1985. Clutch size, nesting success, and predation on nests of Neotropical birds, reviewed. Ornithological Monographs, 36:575-594. http://dx.doi.org/10.2307/40168306

Vuilleumier F, 2003. Neotropical ornithology: Then and now. The Auk, 120:577-590. http://dx.doi. org/0.1642/0004-8038(2003)120[0577:PIONOT]2.0.CO;2

Vuilleumier F, 2004. A critique of Neotropical ornithology: is research on Neotropical birds scientific? Ornitología Neotropical, 15:41-60. 